\title{
Re-challenge with pemetrexed in advanced mesothelioma: a multi-institutional experience
}

\author{
Alessandra Bearz ${ }^{1,9^{*}}$, Renato Talamini ${ }^{2}$, Gilda Rossoni ${ }^{3}$, Antonio Santo ${ }^{4}$, Vincenzo de Pangher ${ }^{5}$, Gianpiero Fasola ${ }^{6}$, \\ Francesco Rosetti ${ }^{7}$, Adolfo Favaretto ${ }^{8}$, Vanesa Gregorc ${ }^{3}$, Massimiliano Berretta ${ }^{1}$, Sandra Santarossa?', \\ Eleonora Berto ${ }^{1}$ and Umberto Tirelli ${ }^{1}$
}

\begin{abstract}
Background: Although first-line therapy for patients affected by advanced mesothelioma is well established, there is a lack of data regarding the impact of second-line treatment.

Methods: We retrospectively collected data of patients affected by advanced mesothelioma, already treated with first-line therapy based on pemetrexed and platin, with a response (partial response or stable disease) lasting at least 6 months, and re-treated with a pemetrexed-based therapy at progression. The primary objective was to describe time to progression and overall survival after re-treatment.

Results: Overall across several Italian oncological Institutions we found 30 patients affected by advanced mesothelioma, in progression after a 6-month lasting clinical benefit following a first-line treatment with cisplatin and pemetrexed, and re-challenged with a pemetrexed-based therapy. In these patients we found a disease control rate of $66 \%$, with reduction of pain in $43 \%$ of patients. Overall time to progression and survival were promising for a second-line setting of patients with advanced mesothelioma, being 5.1 and 13.6 months, respectively.
\end{abstract}

Conclusions: In our opinion, when a patient has a long-lasting benefit from previous treatment with pemetrexed combined with a platin compound, the same treatment should be offered at progression.

\section{Background}

The current standard of care in the management of advanced malignant pleural mesothelioma is a platinumbased chemotherapy [1]; a number of phase II trials have suggested an activity for cisplatin and gemcitabine combination [2,3], while the landmark trial is the one by Vogelzang and Colleagues comparing cisplatin plus pemetrexed to cisplatin alone, demonstrating a survival benefit for the combination of 2.8 months versus cisplatin alone [4]. A subsequent trial showed a 2.6-month improvement in overall survival (OS) for the combination with cisplatin and raltitrexed versus cisplatin alone, 11.4 versus 8.8 months, respectively [5]. Although carboplatin has been shown to be less effective than cisplatin in other malignancies like Non Small-Cell Lung Cancer (NSCLC) [6], when cisplatin is contraindicated for

\footnotetext{
*Correspondence: abearz@cro.it

${ }^{1}$ Medical Oncology, IRCCS, Aviano, PN, Italy

${ }^{9}$ National Cancer Institute of Aviano, Via Franco Gallini 2, Aviano, PN 33081, Italy

Full list of author information is available at the end of the article
}

comorbidities, it may be replaced by carboplatin; moreover several phase I and II trials where carboplatin was combined with pemetrexed or gemcitabine in malignant mesothelioma have given interesting results [7-9]. Due to similar histologic features, treatment for peritoneal mesothelioma has followed the same recommendations $[10,11]$.

No activity for second-line treatment has been clearly reported in patients affected by malignant pleural mesothelioma; pemetrexed alone or combined with platin has shown efficacy even in patients previously treated with other drugs than pemetrexed [12,13], and some activity has been demonstrated for vinorelbine [14].

In absence of a standard second-line treatment for malignant mesothelioma, we hypothesized efficacy from retreatment with pemetrexed alone or in combination with platin, when time to progression (TTP), calculated from the end of first-line chemotherapy and radiologic evidence of progression, was greater or equal than 6 months, as suggested for other pathologies with few therapeutic options [15]. We performed a retrospective
C Biomed Central

(c) 2012 Bearz et al.; licensee BioMed Central Ltd. This is an Open Access article distributed under the terms of the Creative Commons Attribution License (http://creativecommons.org/licenses/by/2.0), which permits unrestricted use, distribution, and reproduction in any medium, provided the original work is properly cited. 
analysis of patients re-treated with pemetrexed-based therapy in second line, to assess our hypothesis.

\section{Methods}

We retrospectively collected patients affected by mesothelioma from several Italian Institutions (IRCCSAviano, IRCCS-S. Raffaele Milan, and General Hospitals of Verona, Gorizia, Udine, Mirano, and Padova), after obtaining approval from IRCCS - Aviano internal ethics committee. In all these Institutions there was the policy to re-treat all patients affected by advanced malignant mesothelioma with the same drugs used in first line, when certain features were observed. Patients had to be treated with a pemetrexed-platin combination as firstline chemotherapy, obtaining partial response (PR) or stable disease (SD), with a further TTP greater or equal than 6 months. We analyzed characteristics and outcome only of those patients treated again with a pemetrexed-based therapy after progression.

The regimens administered as re-treatment were pemetrexed at a dose of $500 \mathrm{mg} / \mathrm{m}^{2}$ combined with a platinum compound (cisplatin at a dose of $75 \mathrm{mg} / \mathrm{m}^{2}$ or carboplatin at an area under the plasma concentrationtime curve -AUC - of $5 \mathrm{mg} / \mathrm{ml} / \mathrm{min}$ ) every three weeks or pemetrexed single agent at a dose of $500 \mathrm{mg} / \mathrm{m}^{2}$ every three weeks, using standard vitamin supplementation and dexamethasone prophylaxis. All the patients had a calculated creatinine clearance value (according to Cockcroft and Gault formula [16]) greater than $45 \mathrm{~mL} / \mathrm{min}$, and good hepatic and bone marrow activity. Before retreatment, all the patients were studied with a chest and abdomen CT scan, repeated every two cycles. Responses were evaluated through RECIST modified criteria for mesothelioma [17]. Information on survival was obtained through an active follow-up based on verification of vital status of the patients, and survival analysis was measured from the date of the first pemetrexedbased re-treatment to death. If survival status was unknown at the final follow-up, OS time was censored at the last contact date. TTP was measured from the beginning of second line of therapy to second relapse. OS and TTP analyses were computed by the Kaplan-Meier method [18], and log-rank test was used to test the difference between subgroups of treatment. In all cases, statistical significant was claimed for $\leq 0.05$.

\section{Results}

Between January 2005 and December 2009 we collected 30 patients from 7 Italian Institutions; their clinical characteristics are reported in Table 1. The majority of all patients were male (77\%); with an ECOG Performance Status (PS) of 1 in 15 patients (50\%) and 0 in 15 (50\%); median age at diagnosis was 64.1 years. Sixteen patients (53\%) had a history of exposition to asbestos, while it
Table 1 Characteristics of $\mathbf{3 0}$ patients with malignant mesothelioma and retreated with pemetrexed-based therapy as second-line therapy

\begin{tabular}{|c|c|}
\hline & N. (\%) \\
\hline N. of patients & $30(100)$ \\
\hline \multicolumn{2}{|l|}{ Histology: } \\
\hline —Epidermoid & $28(93)$ \\
\hline —Mixed & $2(7)$ \\
\hline \multicolumn{2}{|l|}{ Previous surgery: } \\
\hline —Palliative pleural decortications & $11(37)$ \\
\hline —Extrapleural pneumonectomy & $6(20)$ \\
\hline —Videothoracoscopy and pleurodesis & $3(10)$ \\
\hline -Other & $1(3)$ \\
\hline Never & $9(30)$ \\
\hline Median age (years) (range) & $64.1(35-78)$ \\
\hline \multicolumn{2}{|l|}{ Performance Status (ECOG): } \\
\hline-0 & $15(50)$ \\
\hline-1 & $15(50)$ \\
\hline \multicolumn{2}{|l|}{ Sex: } \\
\hline _Female & $7(23)$ \\
\hline —Male & $23(77)$ \\
\hline \multicolumn{2}{|l|}{ Stage at diagnosis (IMIG): } \\
\hline$-\|$ & $9(30)$ \\
\hline 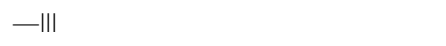 & $8(27)$ \\
\hline$-\mathrm{IV}$ & $12(40)$ \\
\hline -Other & $1(3)$ \\
\hline \multicolumn{2}{|c|}{ Combination of first-line chemotherapy: } \\
\hline —Cisplatin and pemetrexed & $21(70)$ \\
\hline —Carboplatin and pemetrexed & $9(30)$ \\
\hline \multicolumn{2}{|l|}{ Response to first-line treatment: } \\
\hline —Stable Disease & $15(50)$ \\
\hline Partial Response & $15(30)$ \\
\hline
\end{tabular}

was unknown or unclear for all the others. Regarding histology, 28 patients (93\%) were affected by epithelioid mesothelioma, and 2 (7\%) by mixed. At diagnosis, stage IV mesothelioma, according to IMIG classification, was diagnosed in 12 out of 30 patients (40\%), stage III in 8 (27\%), stage II in 9 (30\%), and one patient (3\%) had an extrapleural localization (tunical vaginalis). Nine patients $(30 \%)$ never underwent surgery; while all the other had major surgery, in particular, 11 patients (37\%) had palliative pleural decortication; 6 (20\%) extrapleural pneumonectomy; 3 (10\%) videothoracoscopy and pleurodesis, and 1 (3\%) orchiectomy. Time from surgery to the beginning of treatment with systemic chemotherapy varied between 1 and 30 months; most of the patients received chemotherapy just after recovery from surgery; median time between surgery and the beginning of 
chemotherapy was 6.5 months. Only patients with a tumor assessable before the administration of first line cisplatin and pemetrexed were included in the analysis.

All the patients received a combination of a platin compound and pemetrexed as first line of treatment: 21 patients $(70 \%)$ received cisplatin and pemetrexed, and 9 carboplatin combined with pemetrexed (30\%). The median number of cycles of platin and pemetrexed combination administered as first-line therapy was 5.5 (range: $3-11)$. Response rate was as follows: 15 patients (50\%) showed a stability of the disease, and 15 (50\%) a PR. All of them showed progression, median TTP was 13 months (range: 6-57.5 months). At the beginning of re-treatment with a pemetrexed-based rechallenge, PS (ECOG) was 1 in 21 patients (70\%) and 2 in $9(30 \%)$ (Table 2). For all the patients, pemetrexed-based retreatment was administered as second-line.

Median number of cycles at re-treatment was 4 (range: 3-9). The combination of choice was carboplatin plus pemetrexed in 16 patients (53\%), pemetrexed alone was chosen in 9 patients (30\%), and 5 patients (17\%) received cisplatin and pemetrexed again as they received for firstline.

Modified RECIST criteria were available for 26 patients out of 30; for three patients progression was due to a relapse of pleural effusion and in one patient the retrieval of the radiological images was not possible. Response rate after re-treatment was as follows: 10 patients showed progression of disease (33\%), most of patients

\section{Table 2 Efficacy of re-treatment with pemetrexed-based chemotherapy in $\mathbf{3 0}$ patients affected by malignant mesothelioma}

\begin{tabular}{lr}
\hline & N. (\%) \\
\hline N. of patients & $30(100)$ \\
Regimen of re-treatment: & $9(30)$ \\
-Pemetrexed & $5(17)$ \\
-Cisplatin + pemetrexed & $16(53)$ \\
-Carboplatin + pemetrexed & \\
Response: & $15(50)$ \\
-Stable disease & $5(17)$ \\
-Partial response & $10(33)$ \\
-Disease progression & \\
Performance Status & 0 \\
-0 & $21(70)$ \\
-1 & $9(30)$ \\
Symptom palliation: & \\
-Worsening & $10(33)$ \\
-Absence of pain (before treatment and after) & $7(23)$ \\
-Pain reduction & $13(43)$ \\
\hline
\end{tabular}

had stability of disease, 15 out of 30 patients (50\%), while 5 patients showed a partial response (17\%); median duration of stable disease in patients being retreated was 4.7 months.

TTP calculated from the beginning of re-treatment with pemetrexed-based therapy and radiologic progression was 5.1 months (Figure 1). There was no significant difference between TTP of the group of patients receiving pemetrexed combined with platin or pemetrexed alone as re-challenge, 5.7 versus 4 months, respectively (Figure 2).

Median OS, calculated from the beginning of retreatment to the last contact, was 13.6 months (Figure 3); at the time of analysis at the end of June 2011, 20 patients had died and 10 were still alive.

We also collected information during re-treatment about symptom control, based on VAS patient global assessment $[19,20]$; all the Institutions were involved in a monitoring program to ensure pain control, therefore VAS administration was part of routine care. Pain decreased in 13 out of 30 patients (43\%), 7 patients (23\%) had no pain at all, while 10 patients (33\%) reported a worsening of their pain.

\section{Discussion}

Malignant mesothelioma is a very aggressive disease with poor outcome even when radical surgery is possible; palliative chemotherapy is offered when patients are not candidate for curative surgery; in randomized clinical trials a platin-combination with pemetrexed or raltitrexed have given better results $[4,5]$. Out of those combinations, there are no recommended salvage therapies, when patients experience a progression. For other malignancies, when progression occurs at least 6 months after the end of previous treatment, a rechallenge with the same drugs is offered because an antiblastic activity is considered still possible. Based on the lack of alternatives and in analogy with other malignancies, we proposed a re-treatment with the same therapy used as first-line for patients affected by advanced mesothelioma and progressed after obtaining a benefit from first-line combination with platin and pemetrexed. We collected data about 30 patients from several Italian institutions, where the same policy was applied. We found that re-treatment with pemetrexed was feasible in all our patients; a more frequent combination of pemetrexed with carboplatin instead of cisplatin was chosen, likely due to an effort to avoid neurologic or nephrologic toxicities from cisplatin. Once again an interesting response was obtained, with a clinical benefit observed in 20 out of 30 patients (disease control rate, DCR, 66\%, PR and SD), both by radiological assessment and reduction of pain. Overall TTP and survival were promising for a second-line 


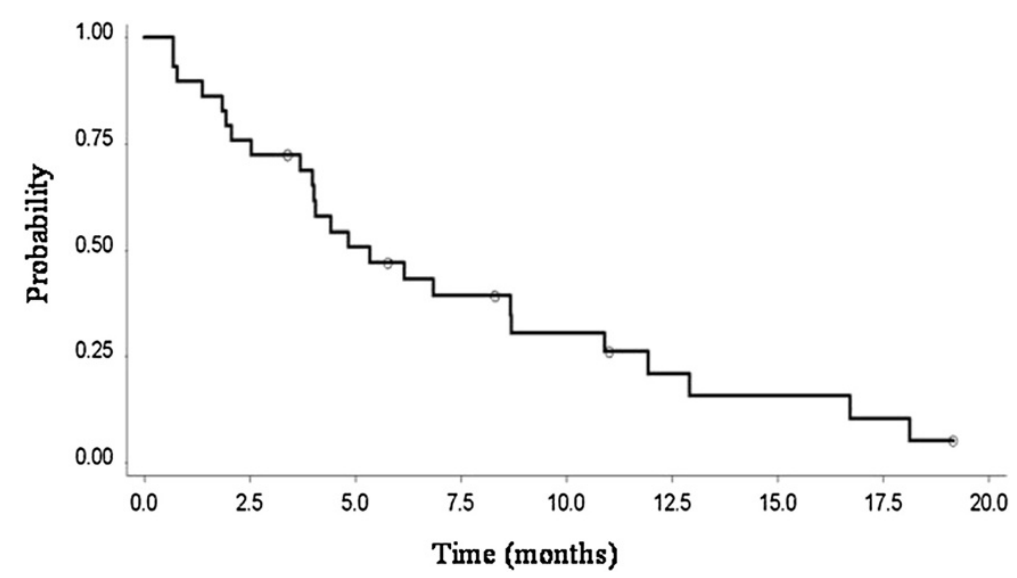

Figure 1 Time to progression of 30 patients affected by mesothelioma and retreated with pemetrexed-based therapy at relapse after first line chemotheraphy.

setting of patients with advanced mesothelioma, 5.1 and 13.6 months, respectively, considering other similar reports from the literature: a French cohort, where several different drugs were used in second-line for patients affected by mesothelioma, showed 3.8 and 12.2 months, respectively for TTP and OS [21], while in a mono-institutional Italian cohort salvage therapy with gemcitabine-platin combination in second or further line demonstrated 3 and 5.5 months, respectively as TTP and OS [22]. We are aware that our group of patients was selected for good prognostic factors, such as PS, benefit after first-line treatment (SD or RP) and a quite long TTP after the end of first-line treatment; moreover no patient was affected by pure sarcomatoid histotype, considered one of the worst prognostic factors $[23,24]$. We found a slightly better trend in TTP for patients treated with a platin-pemetrexed combination even at re-treatment; however, the difference was not statistically significant, and could just underline a better PS or younger age at the base of treatment choice.

At the time of preparation of this manuscript it has been just published a similar experience by Ceresoli and Colleagues [25]. They collected data about a similar casistic of patients, 31 patients, treated in a single Institute. Their population was a little different for the inclusion criteria they set up for re-treatment with the same drugs used as first-line, choosing to re-treat with a pemetrexed-based therapy all the patients with a time to progression greater or equal than 3 months after the end of first line. In the Ceresoli's paper, almost half of patients were re-treated with pemetrexed-combination as second-line, and half as further line of therapy, while all our patients received pemetrexed alone or in combination with a platin compound as second-line therapy only.

The difference in TTP after first-line as inclusion criteria and pemetrexed-based re-treatment used beyond

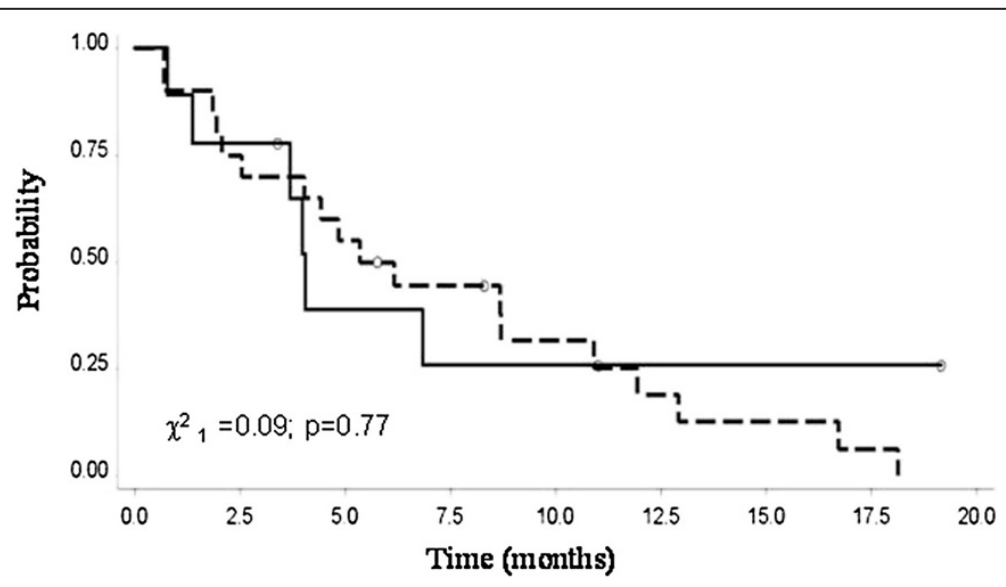

Figure 2 Time to progression of 30 patients with mesothelioma by treatment (_Alimta vs._Platinum+Alimta). 


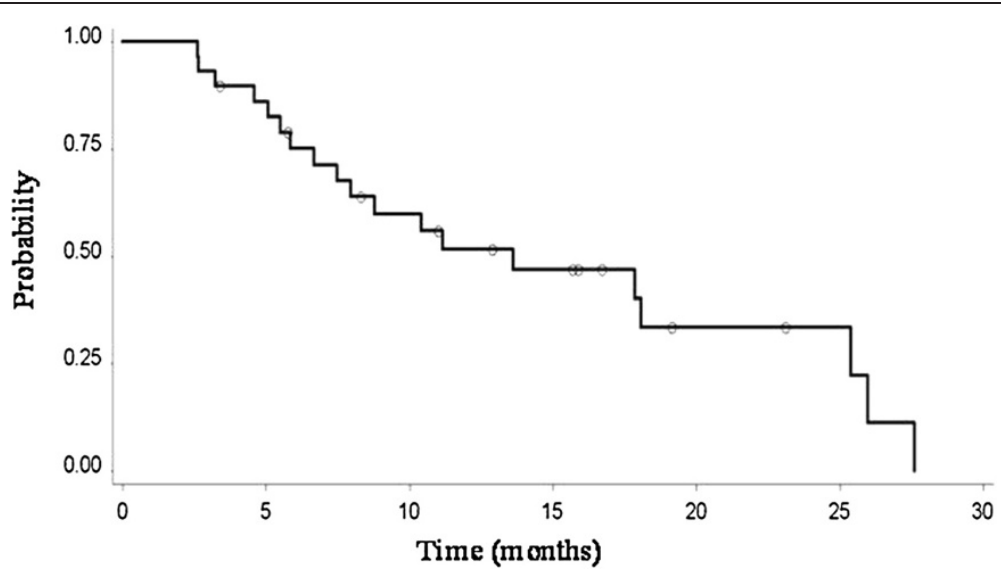

Figure 3 Overall survival of 30 patients affected by mesothelioma and retreated with pemetrexed-based theraph at relapse after first line chemotheraphy.

second-line in almost half of the collected patients may explain the shorter TTP and OS observed in Ceresoli's patients than in ours, 3.8 months and 5.1, respectively, although any significant comparison can be drawn between the two groups of patients.

\section{Conclusions}

Interestingly there are two papers, Ceresoli's and ours, with similar results. Our patients consistently support the data from Ceresoli and Colleagues and strengthen the results, also for the homogenously use of pemetrexed-based re-treatment as second-line and the multi-institutional collection of data. When patients had a benefit from a platin-pemetrexed combination, in the absence of other effective strategies, we strongly suggest a re-treatment with the same drugs, because an improvement of the symptoms and a consistent gain in TTP can be still obtained.

\section{Competing interests}

The authors declare they have no competing interests.

\section{Authors' contributions}

$A B, G R, A S, V d P, G F, F R, A F, M B, S S$ and UT were involved in the conduction of therapy. AB drafted the manuscript. RT was responsible for the statistical analysis. All authors contributed to data interpretation and revised the draft critically for scientific content. EB was responsible for data collection. All authors read and approved the final version of the manuscript.

\section{Acknowledgements}

The authors are indebted to Mrs Paola Favetta for her help in medical writing.

The authors thank all the patients and their families.

\section{Author details}

${ }^{1}$ Medical Oncology, IRCCS, Aviano, PN, Italy. ${ }^{2}$ Unit of Epidemiology and Biostatistics, IRCCS, Aviano, PN, Italy. ${ }^{3}$ Medical Oncology, IRCCS-S Raffaele, Milan, Italy. ${ }^{4}$ General Hospital, GIVOV, Verona, Italy. ${ }^{5}$ General Hospital, Gorizia, Italy. ${ }^{6}$ General Hospital Udine, Udine, Italy. ${ }^{7}$ General Hospital, Mirano, Italy. ${ }^{8}$ IOV Padova, Padova, Italy. ${ }^{9}$ National Cancer Institute of Aviano, Via Franco Gallini 2, Aviano, PN 33081, Italy.
Received: 27 October 2011 Accepted: 23 August 2012

Published: 3 September 2012

\section{References}

1. Lee CW, Murray N, Anderson H, Rao SC, Bishop W: Outcomes with first-line platinum-based combination chemotherapy for malignant pleural mesothelioma: a review of practice in British Columbia. Lung Cancer 2009, 64:308-313.

2. Byrne M, Davidson J, Musk A, Dewar J, van Hazel G, Buck M: Cisplatin and gemcitabine treatment for malignant mesothelioma: a phase II study. J Clin Oncol 1999, 17:25-30.

3. Nowak A, Byrne M, Williamson R, Ryan G, Segal A, Fielding D: A multicentre phase II study of cisplatin and gemcitabine for malignant mesothelioma. Br J Cancer 2002, 87:491-496.

4. Vogelzang N, Rusthoven J, Symanowski J, Denham C, Kaukel E, Ruffie P: Phase III study of pemetrexed in combination with cisplatin versus cisplatin alone in patients with malignant pleural mesothelioma. J Clin Oncol 2003, 21:2636-2644.

5. Van Meerbeck J, Gaafar R, Manegold C, Van Klaveren R, Van Marck E, Vincent M: Randomized phase III study of cisplatin with or without raltitrexed in patients with malignant pleural mesothelioma: an intergroup study of European Organisation for Reasearch and Treatment of Cancer Lung Cancer Group and National Cancer Institute of Canada. J Clin Oncol 2005, 23:6681-6689.

6. Ardizzoni A, Boni L, Tiseo M, Fossella F, Schiller J, Paesmans M: Cisplatin- versus carboplatin-based chemotherapy in first-line treatment of advanced non small-cell lung cancer: an individual patient data meta-analysis. J Natl Cancer Inst 2007, 99:847-857.

7. Hughes A, Calvert P, Azzabi A, Plummer R, Johnson R, Rusthoven J: Phase I clinical and pharmacokinetic study of pemetrexed and carboplatin in patients with malignant pleural mesothelioma. J Clin Oncol 2002, 20:3533-3544

8. Ceresoli G, Zucali P, Favaretto A, Grossi F, Bidoli P, Del Conte G: Phase II study of pemetrexed plus carboplatin in malignant pleural mesothelioma. J Clin Oncol 2006, 24:1443-1448.

9. Favaretto A, Aversa S, Paccagnella A, Vde Manzini P, Palmisano V, Oniga F: Gemcitabine combined with carboplatin in patients with malignant pleural mesothelioma: a multicenter phase II study. Cancer 2003, 97:2791-2793.

10. Byrne MJ, Davidson JA, Musk AW, Dewar J, von Hazel G, Buck M: Cisplatin and gemcitabine treatment for malignant mesothelioma: a phase II study. J Clin Oncol 1999, 17:25-30.

11. Janne PA, Wozniak AJ, Belani CP, Keohan ML, Ross HJ, Polikoff JA: Open-label study of pemetrexed alone in combination with cisplatin for the treatment of patients with peritoneal mesothelioma: outcomes of an expanded access program. Clin Lung Cancer 2005, 7:40-46.

12. Janne PA, Wozniak AJ, Belani CP, Keohan ML, Ross HJ, Polikoff JA: Pemetrexed alone or in combination with cisplatin in previously treated 
malignant pleural mesothelioma: outcomes from a phase IIIB expanded access program. J Thor Oncol 2006, 1:506-512.

13. Jassem J, Ramlau R, Santoro A, Schuette W, Chemaissani A, Hong S, Blatter J, Adachi S, Hanauske A, Manegold C: Phase III Trial of Pemetrexed Plus Best Supportive Care Compared With Best Supportive Care in Previously Treated Patients With Advanced Malignant Pleural Mesothelioma. J Clin Oncol 2008, 26:1698-1704.

14. Steele JP, Shamash J, Evans MT, Gower NH, Tischkowitz MD, Rudd RM: Phase II study of vinorelbine in patients with malignant pleural mesothelioma. J Clin Oncol 2000, 18:3912-3917.

15. Garassino MC, Torri V, Michetti G, Lo Dico M, La Verde N, Aglione S, Mancuso A, Gallerani E, Galetta D, Martelli O, Collovà E: Outcomes of smallcell lung cancer patients treated with second-line chemotherapy: A multi-institutional retrospective analysis. Lung Cancer 2011, 2011(72):378-383

16. Byrne MJ, Nowak K: Modified RECIST criteria for assessment of response in malignant pleural mesothelioma. Ann Oncol 2004, 15:257-260.

17. Cockcroft DW, Gault MH: Prediction of creatinine clearance from serum creatinine. Nephron 1976, 16:31-41

18. Kaplan EL, Meier P: Non-parametric estimation from incomplete observations. J Am Stat Assoc 1958, 53:457-481

19. Huskisson EC: Measurement of pain. Lancet 1974, 2:1127-1131.

20. Mccormack HM, Horne DJ, Sheather S: Clinical applications of visual analogue scales: a critical review. Psychol Med 1988, 18:1007-1119.

21. Margery J, Riviere F, Planchard D, Le Floch H, Ferrand FR, Mairovitz A, Besse $B$, Vaylet $F$, Ruffie $P$ : Second-line therapy in patients with malignant pleural mesothelioma. A French retrospective study (2005-2006). Rev Pneumol Clin 2010, 66:255-259.

22. Pasello G, Nicotra S, Marulli G, Rea F, Bonanno L, Carli P, Magro C, Jirillo A, Favaretto A: Platinum-based doublet chemotherapy in pre-treated malignant pleural mesothelioma (MPM) patients: A mono-institutional experience. Lung Cancer 2011, 73:351-355.

23. Schramm A, Opitz I, THies S, Seifert B, Moch H, Weder B, Soltermann A: Prognostic significance of epithelial-mesenchymal transition in malignant pleural mesothelioma. Eur J Cardiothorac Surg. 2010, 37:566-572.

24. Baas P: Predictive and prognostic factors in malignant pleural mesothelioma. Curr Opin Oncol 2003, 15:127-130.

25. Ceresoli G, Zucali PA, De Vincenzo F, Gianoncelli L, Simonelli M, Lorenzi E, Ripa C, Giordano L, Santoro A: Retreatment with pemetrexed based chemotherapy in patients with malignant pleural mesothelioma. Lung Cancer 2011, 72:73-77.

doi:10.1186/1756-0500-5-482

Cite this article as: Bearz et al:: Re-challenge with pemetrexed in advanced mesothelioma: a multi-institutional experience. BMC Research Notes 2012 5:482.

\section{Submit your next manuscript to BioMed Central and take full advantage of:}

- Convenient online submission

- Thorough peer review

- No space constraints or color figure charges

- Immediate publication on acceptance

- Inclusion in PubMed, CAS, Scopus and Google Scholar

- Research which is freely available for redistribution 